\title{
Adsorption of Phosphate by Cerium Hydroxide
}

\author{
Fumihiko Ogata, Kouzou Takahashi, Hisato Tominaga, Hitoshi Yabutani, and Naohito Kawasaki* \\ Faculty of Pharmacy, Kinki University, 3-4-1 Kowakae, Higashi-Osaka, Osaka 577-8502, Japan
}

(Received 17 May 2010; Accepted 19 May 2010; Published 25 May 2010)

\begin{abstract}
This study investigated the ability of cerium hydroxide (CE) to adsorb phosphate, and compared it to the aluminum compounds boehmite (BE) and gibbsite (GB), which possess high phosphate adsorption ability. Specific surface area, number of hydroxyl groups, and amount of phosphate adsorbed were measured. Results indicated that specific surface area increased in the order $\mathrm{GB}<\mathrm{CE}<\mathrm{BE}$, number of hydroxyl groups increased $\mathrm{GB}<\mathrm{BE}<\mathrm{CE}$, and amount of phosphate adsorbed increased $\mathrm{GB}<\mathrm{BE}<\mathrm{CE}$. These results showed that the adsorption mechanism of phosphate using CE was more closely related to chemical factors involved in the exchange of phosphate with hydroxyl groups onto CE than to physical factors such as specific surface area. [DOI: 10.1380/ejssnt.2010.258]
\end{abstract}

Keywords: Cerium hydroxide; Phosphate; Ion exchange

\section{INTRODUCTION}

Phosphate has received attention because of its role in eutrophication and its limited abundance in nature. Methods for the removal and reuse of phosphate have been reported. For example, layered double hydroxides (LDHs) [1-4], inorganic materials including metal oxide hydroxides [5], metal oxides [6], and enhanced biological phosphorus removal (EBPR) processes [7] have been investigated. The adsorption mechanism of these methods involved ion exchange, ligand exchange with surface hydroxyl groups to create inner-sphere complexation, bonding between adsorbed phosphate and adsorptive sites on the surface, dissolution-coagulation, and surface precipitation. A previous report described the phosphate adsorption ability of boehmite (BE) and gibbsite (GB), which involves an adsorption mechanism of ion exchange with hydroxyl groups and the surface [8-11]. BE and GB also possessed the ability to adsorb arsenic and chromium ions $[12,13]$.

However, cerium is the most abundant of the rare earth elements. The concentration of cerium is $46 \mathrm{mg} / \mathrm{g}$ in the earth's crust, greater than that of lead $(16 \mathrm{mg} / \mathrm{g})$ and

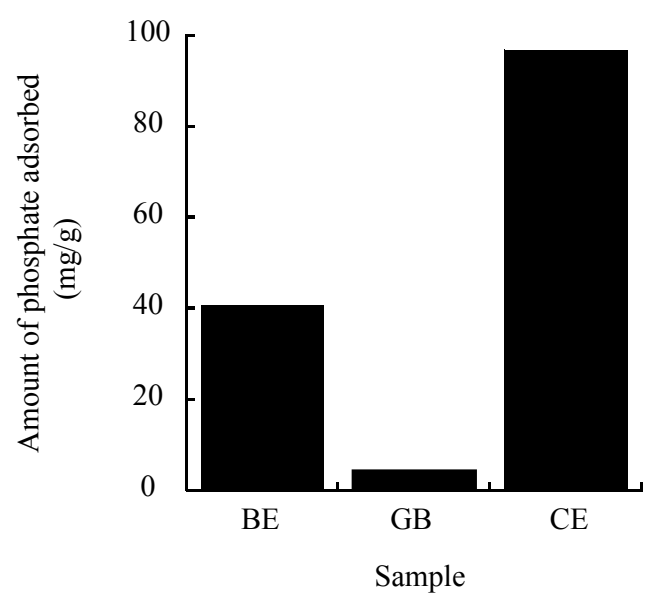

FIG. 1: Amount of phosphate adsorbed onto BE, GB and CE.

*Corresponding author: kawasaki@phar.kindai.ac.jp zinc $(40 \mathrm{mg} / \mathrm{g})$. Considering the residual amount of rare earth elements in the earth's crust, it is likely they will be mined for another 1200 years [14]. Cerium is used as an abradant, as a decolorization agent for glass, and as a catalyst, especially for water purification. In particular, adsorption of arsenic by cerium has been reported $[15,16]$. Cerium can maintain hydroxyl group on its surface as well as BE and GB. However, there are no reports regarding the adsorption of phosphate by cerium.

In this study, the ability of cerium to adsorb phosphate was investigated because cerium can maintain hydroxyl groups on its surface and has an arsenic adsorption ability similar to that of BE and GB.

\section{EXPERIMENTAL}

\section{A. Materials}

AD220NS (Tomita Pharmaceutical Co., Ltd., Japan) was used as BE. For the BE, noncrystalline aluminum hydroxide was placed in an aqueous medium, and after heat treatment at $90-100^{\circ} \mathrm{C}$ for $1-3 \mathrm{~h}$, the aluminum oxyhydroxide obtained was spray-dried. Its chemical composition was $69.5 \% \mathrm{Al}_{2} \mathrm{O}_{3}$, with less than $0.1 \% \mathrm{Cl}^{-}$and less than $0.8 \% \mathrm{SO}_{4}^{2-}$. Loss of mass upon drying, $\mathrm{pH}$, mean particle size, and pore volume were $7.8 \%, 8.2,100 \mu \mathrm{m}$, and $0.402 \mathrm{~mL} / \mathrm{g}$, respectively. GB (GBH-42M) was purchased from Showa Denko (Japan). Its adhesion moisture was $0.23 \%$, and the composition was $99.6 \% \mathrm{Al}(\mathrm{OH})_{3}, 0.01 \%$ $\mathrm{Fe}_{2} \mathrm{O}_{3}, 0.01 \% \quad \mathrm{SiO}_{2}, 0.33 \% \quad \mathrm{Na}_{2} \mathrm{O}$ and $0.05 \% \omega-\mathrm{Na}_{2} \mathrm{O}$. Mean particle size, bulk density (light), bulk density (heavy), and moisture adsorption capacity were $1.1 \mu \mathrm{m}$, $0.2 \mathrm{~g} / \mathrm{cm}^{3}, 0.5 \mathrm{~g} / \mathrm{cm}^{3}$, and $0.90 \%$, respectively. Cerium hydroxide (CE) was purchased from Wako Pure Chemical Industries Co., Ltd. $\mathrm{CE}$ was included as $\mathrm{CeO}_{2}$ at $80-87 \%$; solubility was good in acidic solution, but was poor in alkaline solution.

The number of hydroxyl groups was calculated from the amount of adsorbed fluoride ion as follows [17]: $1.25 \mathrm{~g}$ of adsorbent was added to $50 \mathrm{~mL}$ of $0.01 \mathrm{~mol} / \mathrm{L} \mathrm{NaF}$ solution at $\mathrm{pH} 4.6$, which was then adjusted using $0.2 \mathrm{~mol} / \mathrm{L}$ acetic acid and $0.2 \mathrm{~mol} / \mathrm{L}$ sodium acetate buffer. The solution was shaken at $25^{\circ} \mathrm{C}$ for $24 \mathrm{~h}$ at $100 \mathrm{rpm}$ and then filtrated using a $0.45-\mu \mathrm{m}$ membrane filter. The concentration of fluoride ions in the filtrated solution was measured [18], and the amount of fluoride ion adsorbed onto adsorbent 
TABLE I: Specific surface area and number of hydroxyl group of BE, GB and CE.

\begin{tabular}{cccc}
\hline \hline Sample & $\begin{array}{c}\text { Specific surface } \\
\text { area }\left(\mathrm{m}^{2} / \mathrm{g}\right)\end{array}$ & $\begin{array}{c}\text { Number of hydroxyl } \\
\text { group }(\mathrm{mmol} / \mathrm{g})\end{array}$ & $\begin{array}{c}\text { Number of hydroxyl group versus } \\
\text { specific surface area }\left(\mathrm{mmol} / \mathrm{m}^{2}\right)\end{array}$ \\
\hline $\mathrm{BE}$ & 297.0 & 0.55 & 0.002 \\
$\mathrm{~GB}$ & 4.2 & 0.15 & 0.036 \\
$\mathrm{CE}$ & 100.1 & 1.20 & 0.012 \\
\hline \hline
\end{tabular}

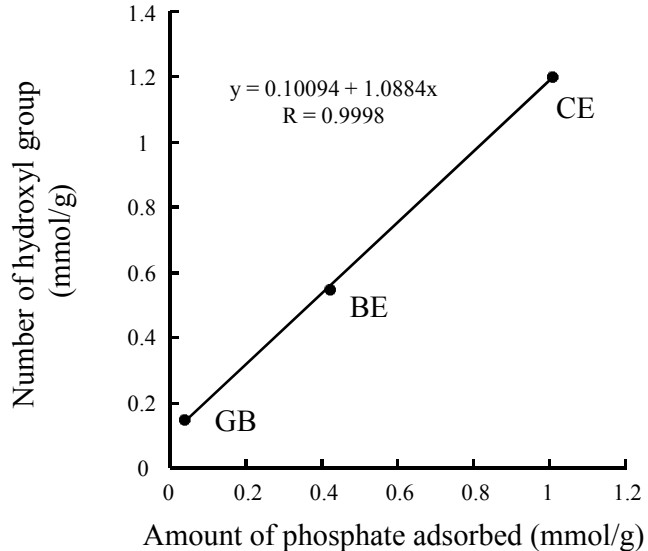

FIG. 2: Relationship between amount of phosphate adsorbed and number of hydroxyl group.

was calculated. Specific surface area was measured using NOVA4200e (Quantachrome Co., Ltd. Japan).

\section{B. Adsorption of phosphate}

Potassium dihydrogenphosphate was purchased from Wako Pure Chemical Industries Co., Ltd. The amount of phosphate adsorbed was measured by the following procedure: $0.05 \mathrm{~g}$ of adsorbent was added to $50 \mathrm{~mL}$ of phosphate solution at an initial concentration 1110$1150 \mathrm{mg} / \mathrm{L}$. The solution was shaken at $25^{\circ} \mathrm{C}$ for $24 \mathrm{~h}$ at $100 \mathrm{rpm}$ and then was filtrated using a $0.45-\mu \mathrm{m}$ membrane filter. The concentration of phosphate was measured using DR/890 (HACH, U.S.A.). The amount of phosphate adsorbed onto the adsorbent was calculated using the concentrations before and after adsorption as follows:

$$
X=\left(C_{0}-C\right) V / M,
$$

where $X$ is the amount of phosphate adsorbed $(\mathrm{mg} / \mathrm{g}), C_{0}$ is the concentration before adsorption $(\mathrm{mg} / \mathrm{L}), C$ is the concentration after adsorption $(\mathrm{mg} / \mathrm{L}), V$ is the solvent volume $(L)$, and $M$ is the mass of adsorbent $(\mathrm{g})$.

\section{RESULTS AND DISCUSSION}

The specific surface area, number of hydroxyl groups, and number of hydroxyl groups per unit of BE, GB, and $\mathrm{CE}$ are shown in Table I. Results indicated that specific surface area increased in the order $\mathrm{GB}<\mathrm{CE}<\mathrm{BE}$, while the number of hydroxyl groups increased in the order GB (a)
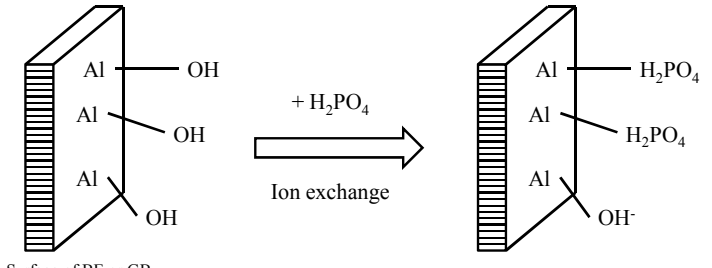

$\mathrm{OH}^{-}$

$\mathrm{OH}$

(b)
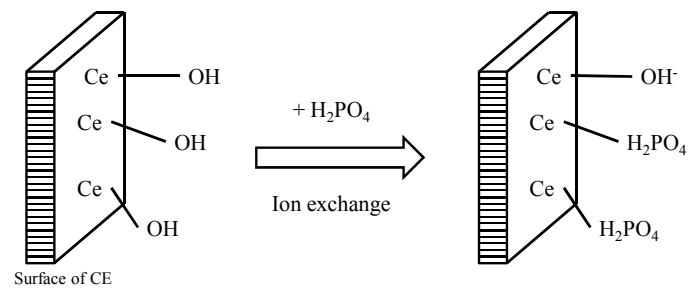

$\mathrm{OH}^{-}$

$\mathrm{OH}^{-}$

FIG. 3: Adsorption mechanism of phosphate onto BE, GB and CE. (a): Surface reaction of BE or GB, (b): surface reaction of CE.

$<\mathrm{BE}<\mathrm{CE}$. Reports have demonstrated that the amount of phosphate adsorbed using untreated $\mathrm{BE}$ was greater than that using untreated GB, and adsorption of phosphate was related to specific surface area and the number of hydroxyl groups on the surface $[8,9]$. The data in Fig. 1 shows that the amount of phosphate adsorbed by $\mathrm{BE}, \mathrm{GB}$, and $\mathrm{CE}$ was $40.47,3.50$, and $96.64 \mathrm{mg} / \mathrm{g}$, respectively. This indicates that adsorption of phosphate using CE was more closely related to chemical factors involving exchange of phosphate with hydroxyl groups on the surface than to physical factors such as specific surface area. In addition, a comparison of the number of hydroxyl groups on the surface per unit with the amount of phosphate adsorbed and the amount of phosphate adsorbed by $\mathrm{GB}$, the number of hydroxyl groups on the surface reached a maximum of $0.036 \mathrm{mmol} / \mathrm{m}^{2}$, lower than that found with other adsorbents. However, this is probably a suitable number of hydroxyl groups on the surface, because of the difficulty in the ion exchange of phosphate and the potential for steric hindrance. The $\mathrm{pH}$ of the solution after adsorption of phosphate shifted to basic. Moreover, the relationship between the number of hydroxyl groups on the surface and the amount of phosphate adsorbed by $\mathrm{CE}$ (Fig. 2) indicated that the main adsorption mechanism of phosphate adsorption was ion exchange between phosphate and the hydroxyl groups on the surface (Figure 3 shows surface reaction between phosphate and number of hydroxyl groups on the surface). The linear equation in Fig. 2 indicated that 1:1 ion exchange occurred between phosphate and hydroxyl groups on the surface. The characteristics of $\mathrm{CE}$ and the adsorption mechanism of phosphate using $\mathrm{CE}$ also were investigated in detail. 


\section{CONCLUSIONS}

Among BE, GB, and CE, the specific surface area of $\mathrm{BE}$ was greatest, and the number of hydroxyl groups of $\mathrm{CE}$ was the greatest. The amount of phosphate adsorbed increased in the order $\mathrm{GB}<\mathrm{BE}<\mathrm{CE}$. The adsorption mechanism of phosphate using $\mathrm{CE}$ was more closely related to the number of hydroxyl groups than to specific surface area. Moreover, measurement of the number of hydroxyl groups per unit indicated that a suitable number of hydroxyl groups were present on the surface compared to the amount of phosphate adsorbed. The relationship between the number of hydroxyl groups on the surface and the amount of phosphate adsorbed by CE indicated that the main adsorption mechanism of phosphate was ion exchange with hydroxyl groups on the surface.

\section{Acknowledgments}

This work was financially supported by "Antiaging Center Project" for Private Universities from Ministry of Education, Culture, Sports, Science and Technology, 2008-2012.
[1] X. Cheng, X. Huang, X. Wang, D. Sun, J. Hazard. Mater. 177, 516 (2010).

[2] H. He, H. Kang, S. Ma, Y. Bai, and X. Yang, J. Colloid Interface Sci. 343, 225 (2010).

[3] Y. Seida and Y. Nakano, Water Res. 36, 1306 (2002).

[4] S.-L. Wang, C.-Y. Cheng, Y.-M. Tzou, R.-B. Liaw, T.W. Chang, J.-H. Chen, and J. Hazard. Mater. 147, 205 (2007).

[5] R. Chitrakar, S. Tezuka, A. Sonoda, K. Sakane, K. Ooi, and T. Hirotsu, J. Colloid Interface Sci. 298, 602 (2006).

[6] L. A. Rodrigues and M. L. C. P. da Silva, Colloids Surf. A 334, 191 (2009)

[7] T. Mino, M. C. M. VanLoosdrecht, and J. J. Heijnen, Water Res. 32, 3193 (1998).

[8] S. Tanada, M. Kabayama, N. Kawasaki, T. Sakiyama, T. Nakamura, M. Araki, and T. Tamura, J. Colloid Interface Sci. 257, 135 (2003).

[9] M. Kabayama, T. Sakiyama, N. Kawasaki, T. Nakamura, M. Araki, and S. Tanada, J. Chemical Engineer. Japan 36, 499 (2003).
[10] M. Kabayama, N. Kawasaki, T. Nakamura, and S. Tanada, e-J. Surf. Sci. Nanotech. 3, 63 (2005).

[11] N. Kawasaki, F. Ogata, K. Takahashi, M. Kabayama, K. Kakehi, and S. Tanada, J. Health Sci. 54, 324 (2008).

[12] F. Ogata, N. Kawasaki, T. Nakamura, and S. Tanada, J. Colloid Interface Sci. 300, 88 (2006).

[13] F. Ogata, N. Kawasaki, M. Kabayama, and K. Kakehi, Chem. Pharm. Bull. 57, 129 (2009).

[14] G. Adachi, Kidoruimonogatari (Sangyotosho, Tokyo, 1991), P. 9 (in Japanese).

[15] M. Shirato, K. Wakabayashi, and N. Suzuki, Environmental Conservation Engineering 29, 122 (2000) (in Japanese).

[16] M. Shiratsuchi, Shigen Kankyo Taisaku 37, 1469 (2001) (in Japanese).

[17] H. P. Boehm, Angew. Chem. 78, 617 (1966).

[18] H. Yamashita, Y. Ozawa, F. Nakajima, and T. Murata, Nippon Kagaku Kaishi 8, 1057 (1978) (in Japanese). 